OmniAkuatika, 11 (2): 33-40, 2015
ISSN: 1858-3873 print / 2476-9347 online
Research Article

\title{
KARAKTERISTIK GELOMBANG SIGNIFIKAN DI SELAT KARIMATA DAN LAUT JAWA BERDASARKAN RERATA ANGIN 9 TAHUNAN (2005-2013)
}

\author{
Sigit Wicaksana ${ }^{[1,4]}$, Ibnu Sofian ${ }^{[2]}$, Widodo Pranowo ${ }^{3}$, \\ Anastasia Rita Tisiana Dwi Kuswardani ${ }^{[3]}$, Saroso ${ }^{[4]}$ dan Nahwanto Budi Sukoco ${ }^{[4]}$ \\ ${ }^{[1]}$ Sekolah Tinggi Teknologi Angkatan Laut (STTAL), Prodi. S1 Hidrografi Angkatan XXXIII \\ ${ }^{[2]}$ J. Raya Jakarta - Bogor KM. 46, Cibinong, Jawa Barat 16911, Indonesia \\ Telepon : +62-21-8753155 \\ ${ }^{[3]}$ Laboratorium Data Laut dan Pesisir, Pusat Litbang Sumberdaya Laut dan Pesisir, Badan Litbang Kementerian \\ Kelautan dan Perikanan, Jalan Pasir Putih I Ancol Timur, Jakarta. 14430. Telp/Fax. +62-21-64711654, \\ ${ }^{[4]}$ Dinas Hidro-Oseanografi, TNI Angkatan Laut, Ancol Timur, Jakarta 14430. \\ *Corresponding author : widodo.pranowo@gmail.com
}

\begin{abstract}
Karimata strait and the java sea is one of the most densely shipping lanes in the maritime country of Indonesia. Information of a significant wave is needed to safety navigation. The prediction of a significant wave mostly employs the modeling using wind as input data to produce an early warning warning prediction. Characteristic of a significant wave shows the maximum wave height in the strait and the java sea karimata occurs in west monsoon (January) and east season (August) every year. Especially at the peak of west monsoon (January) maximum wave height reach 1.5-3 meters in Karimata Strait, and reach 0.5-2.5 meters in Java Sea. The frequency of significant wave occurences mostly extend until February, where wave height in Java Sea will stay the same (0.5-2.5 meters), while in Karimata Strait is little bit decrease (1-2.5 meters). Recommended to all sea transportation users, in those regions during January and February, to avoid using ship with the hull is less than 3 meters height.
\end{abstract}

Keywords: significant wave characteristic, Karimata Strait, Jawa Sea, Wind, Modeling

\section{PENDAHULUAN}

Indonesia merupakan Negara kepulauan yang terbesar di dunia. Setiap pulaunya dipisahkan oleh lautan yang berjauhan jaraknya sehingga, segala aktivitas penduduknya mengandalkan transportasi laut sebagai contoh dalam distribusi bahan makanan, bahan baku energi, bahan baku bangunan, dan lain sebagainya. Aktivitas kependudukan di Indonesia saat ini masih terpusat di dua pulau yaitu Pulau Jawa dan Pulau Sumatera. Lalu lintas pelayaran di wilayah ini sangatlah padat.

Berdasarkan data dari Badan Pusat Statistik (BPS) pada tahun 2012, penduduk Indonesia mencapai sekitar 257.516.167 jiwa. Sementara itu, hasil sensus penduduk tahun 2010 menunjukkan jumlah penduduk Indonesia mencapai 237.641.326 jiwa, dengan besar wilayah daratan Negara Indonesia mencapai luas sampai dengan $1.904 .569 \mathrm{~km}^{2}$. (BPS, 2014).Aktivitas transportasi laut ini sangat bergantung pada kondisi cuaca maritim antara lain angin dan gelombang. Gelombang laut yang terjadi dapat dipicu oleh berbagai hal seperti angin, aktivitas lempeng bumi, akibat gerakan kapal, pasang surut, dan arus laut (Pranowo, 2014). Namun yang paling sering terjadi adalah gelombang yang dibangkitkan oleh angin. Terutama jika terjadi angin kencang, biasanya akan mengakibatkan gelombang tinggi. Cuaca buruk seperti gelombang tinggi dan angin kencang tersebut sering kali menghambat aktivitas pelayaran. Jika prediksi gelombang laut ini dapat dilakukan dengan baik, maka tindakan antisipasi dapat diambil oleh para pengguna transportasi laut. Penggerak utama gelombang di laut adalah medan angin yang tepat berada diatasnya, sehingga kondisi gelombang sangat tergantung pada kondisi angin lokal (Purba dan Pranowo, 2015).

Pada abad IX-X Selat Karimata sampai dengan Pulau Jawa merupakan salah satu jalur perdagangan laut. Dimana pada era tersebut perdagangan melalui jalur lalu lintas laut dari Selat Malaka sampai Laut Jawa di kuasai oleh 
Kerajaan Sriwijaya. Ini terbukti dengan banyak ditemukannya benda arkeologi yang tenggelam pada daerah jalur pelayaran antara Selat Malaka menuju Laut Jawa (Pranowo et al., 2012).

Gelombang yang terjadi di laut merupakan gerakan naik turunnya muka laut yang timbul akibat adanya gangguan pada badan air, misalnya angin, gempa bumi akibat gerakan tektonik maupun vulkanik, dan gaya tarik benda-benda langit. Gelombang adalah profil elevasi permukaan laut yang didefinisikan dari suatu titik still water level (SWL) yang akan membentuk puncak berikutnya. Elevasi permukaan air laut selalu bernilai positif sedangkan tinggi gelombang dapat bernilai positif (Holthuijen, 2007).

Gelombang laut merupakan salah satu komponen laut yang mempunyai pengaruh besar pada aktivitas kehidupan yang berada di lautan, kebutuhan untuk memperkirakan gelombang laut sendiri mulai di rasa menjadi salah satu kebutuhan yang sangat penting, dengan adanya informasi gelombang laut di kemudian hari maka segala aktivitas kehidupan yang terpengaruh dengan gelombang laut seperti transportasi laut dan bernavigasi pada khususnya akan dapat dipersiapkan dengan baik (Deny, 2004; Purba dan Pranowo, 2015).

Di Laut Jawa bagian barat, gelombang secara fisis lebih mendapat pengaruh dari Laut Cina Selatan di bandingkan dengan Samudera Hindia. Hal ini dikarenakan celah yang menghubungkan Laut Cina Selatan yakni Selat Karimata lebih luas dibanding celah dari Samudera Hindia yakni Selat Sunda (Sofian dan Wijanarto, 2008; Sofian, 2011).

Transfer energi dari angin ke gelombang dapat terjadi karena momentum stress permukaan oleh angin. Fluktuasi tekanan udara berhubungan dengan aliran udara di atas permukaan laut dan cukup untuk menyebabkan gangguan permukaan air laut (WMO, 1998).

\section{METODOLOGI PENELITIAN}

Metode penelitian diawali dengan melakukan studi pustaka tentang teori gelombang, studi pemrograman Wave-Watch III (Tolman, 2002), dilanjutkan dengan mempelajari tulisan, tugas akhir atau makalah terdahulu tentang gelombang serta mempelajari keadaan gelombang di Selat Karimata dan Laut Jawa.

Dalam menentukan estimasi gelombang signifikan di Selat Karimata dan Laut Jawa terdapat 2 parameter yang harus di perhatikan yaitu kondisi angin dan ketinggian gelombang (Kurniawan dkk., 2012; Pranowo, 2012). Selain itu juga diperhatikan masalah batimetri pada daerah tersebut yang menjadi bagian penting dari analisis tinggi gelombang itu sendiri (Purba dan Pranowo, 2015). Data yang digunakan adalah angin rerata harian 2005 - 2013 meter diatas permukaan laut yang digunakan diambil dari NCEP NOAA (Tolman \& Chalikov, 1996; Saha et al., 2014), dan batimetri hasil digitasi dari Peta Laut No. 66, 149 dan S-23 yang melingkupi Selat Karimata dan Laut Jawa Dishidros TNI-AL (Sofian dan Wijanarto, 2008). Adapun visualisasi hasil simulasi gelombang yang ditampilkan berupa rerata 2005-2013 dilakukan dengan menggunakan Ferret dengan resolusi spasial 20 arc-minute atau $\pm 37 \mathrm{~km}$ (Hankin et al., 2007). Diagram alir pemodelan gelombang signifikan dapat dilihat pada Gambar 1. Pada analisis karakteristik gelombang signifikan ini tidaklah dilakukan validasi, karena model Wave Watch III telah divalidasi oleh Sofian et al. (2008) di Laut Jawa, dan seluruh perairan Indonesia pada umumnya dengan tingkat akurasi sebesar $81 \%$ (Sofian, 2010).

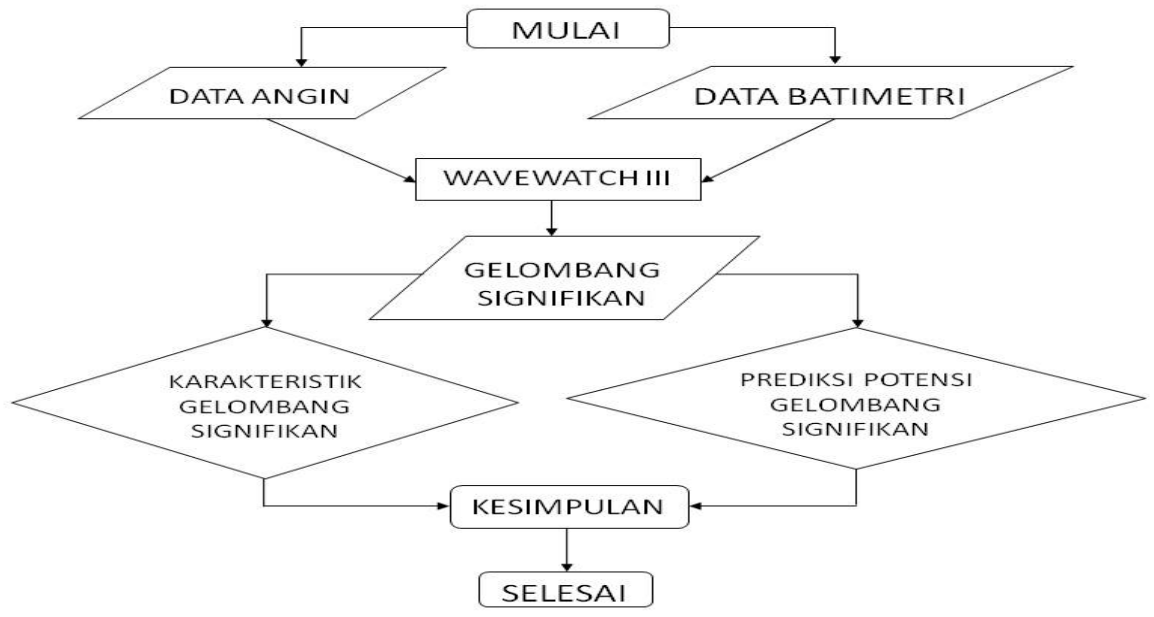

Gambar 1. Diagram alir pemodelan gelombang signifikan 

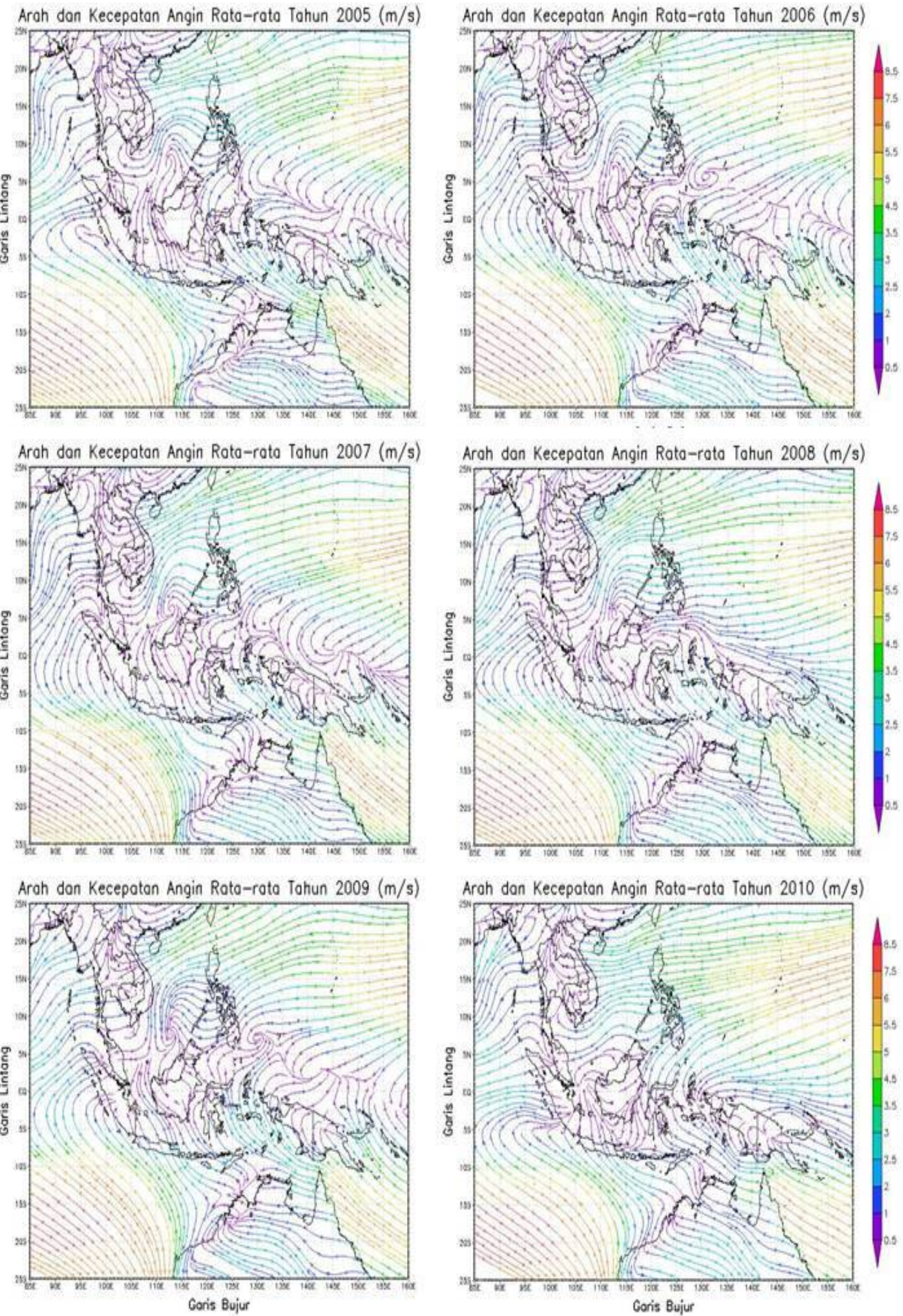

Gambar 2. Distribusi pola pergerakan angin (streamline) secara umum di Indonesia rerata tahunan 2005 - 2010 dengan sumber data dari NCEP Reanalysis Data. 

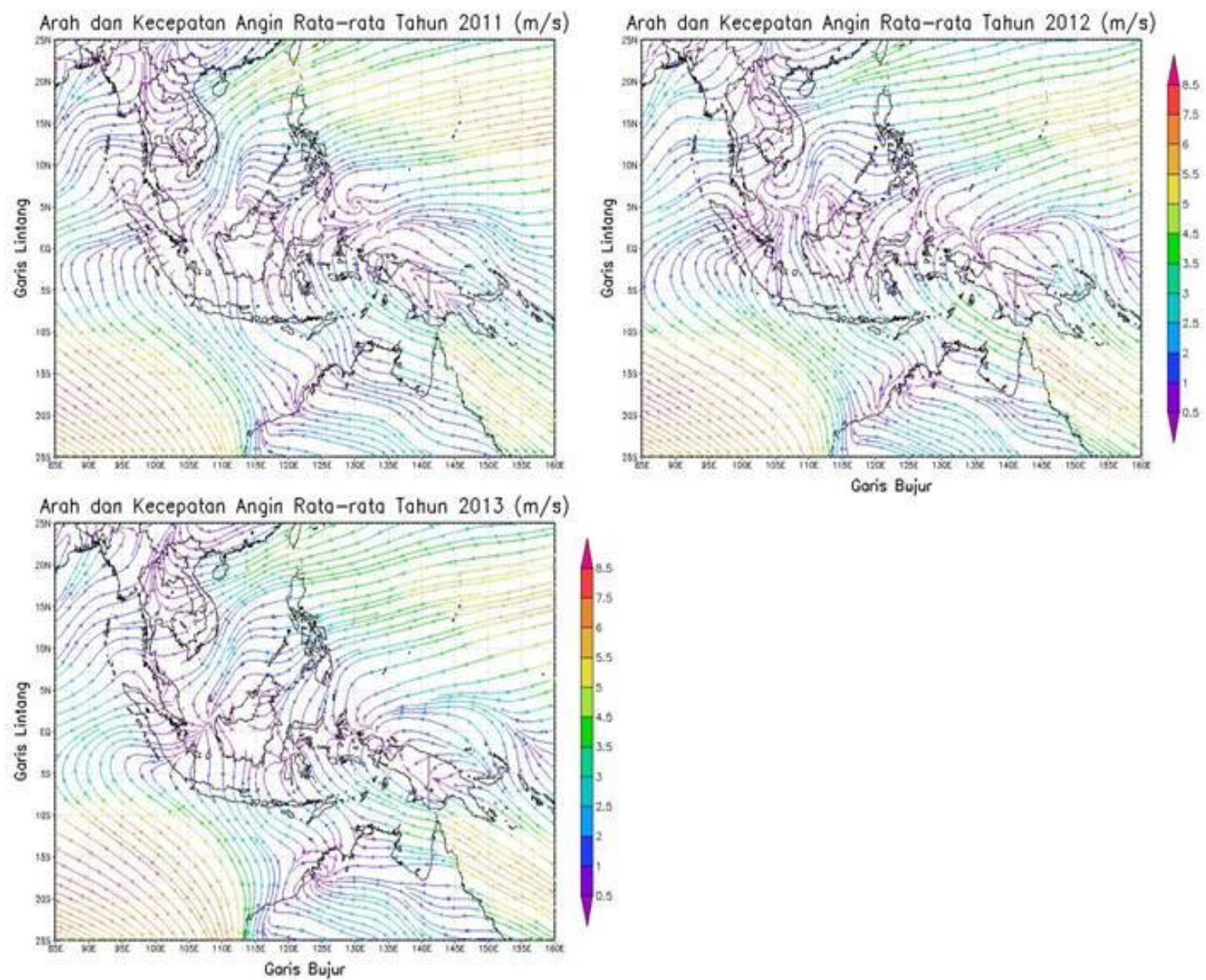

Gambar 3. Distribusi pola pergerakan angin (streamline) secara umum di Indonesia rerata tahunan 2011 - 2013 dengan sumber data dari NCEP Reanalysis Data.

\section{HASIL DAN PEMBAHASAN}

\section{Karakteristik Pola Angin}

Secara umum rerata tahunan 2005-2013 pola angin di Selat Karimata dan Laut Jawa di Indonesia adalah bergerak dari SelatanTenggara menuju ke Utara-Baratlaut, lihat Gambar 2 - 3. Namun apabila direratakan pada bulan Januari yang mewakili kondisi puncak dari musim Barat, lihat Gambar 4 - 5, maka pola angin umumnya bergerak dari Utara-Baratlaut menuju Selatan-Timur. Pengaruh angin monsun kental mempengaruhi kedua wilayah perairan tersebut (Purba dan Pranowo, 2015). Berdasarkan data kecelakaan kapal perang dan dagang (karamnya kapal) pada kurun waktu tahun 1400-1900 era jalur perdangangan laut yang dikenal sebagai jalur sutra laut, pada zaman itu dimana teknologi perkapalan (gyro compass, weather system, radar, sonar) belum secanggih sekarang, 91\% kecelakaan kapal di Selat Karimata dan Laut Jawa adalah diakibatkan oleh kondisi cuaca buruk di laut, terutama pada Musim Barat (Pranowo et al., 2012). Dalam hal ini faktor cuaca seperti angin dan gelombang sangatlah penting bagi pergerakan kapal-kapal (layar) perang/dagang tersebut. Selat Karimata hingga saat ini masih menjadi jalur perdanganan yang dikenal sebagai Alur Lintas Kepulauan Indonesia (ALKI) I dan Laut Jawa menjadi salah satu alur pelayanan nasional yang penting, terutama pada masa sekarang (20142019) berperan dalam jalut tol laut nasional.

Pergerakan angin di Selat Karimata mendapatkan pengaruh dari utara khatulistiwa yakni dari perairan Laut Cina Selatan. Selain itu secara topografi, Selat Karimata mempunyai karakteristik daerah terbuka, sehingga angin akan sangat mudah bergerak pada wilayah tersebut. Rerata kecepatan angin tertinggi wilayah di Selat Karimata adalah terjadi pada Januari yang mewakili musim Barat (5-8 meter/detik) dan Agustus yang mewakili Musim Timur (5-9 meter/detik), lihat Gambar 4 dan Tabel 1. 


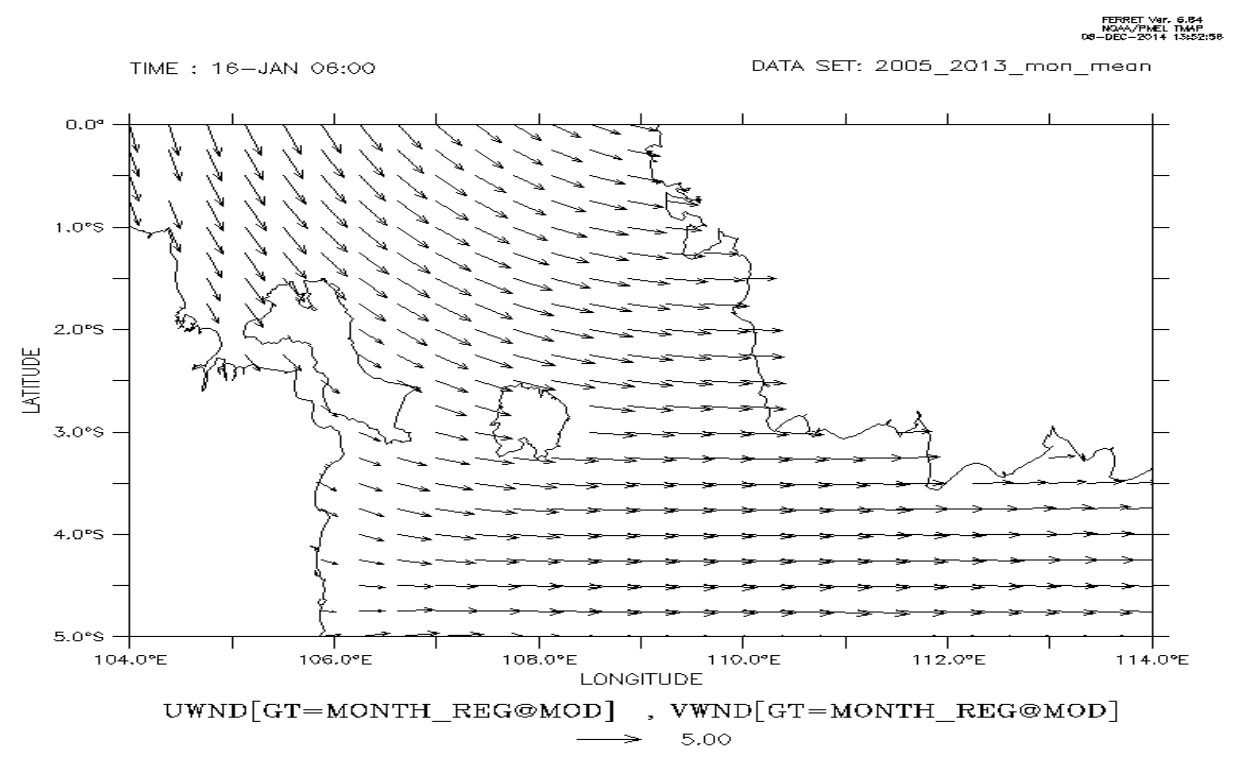

Gambar 4. Distribusi pola angin di Selat Karimata rerata Januari 2005-2013

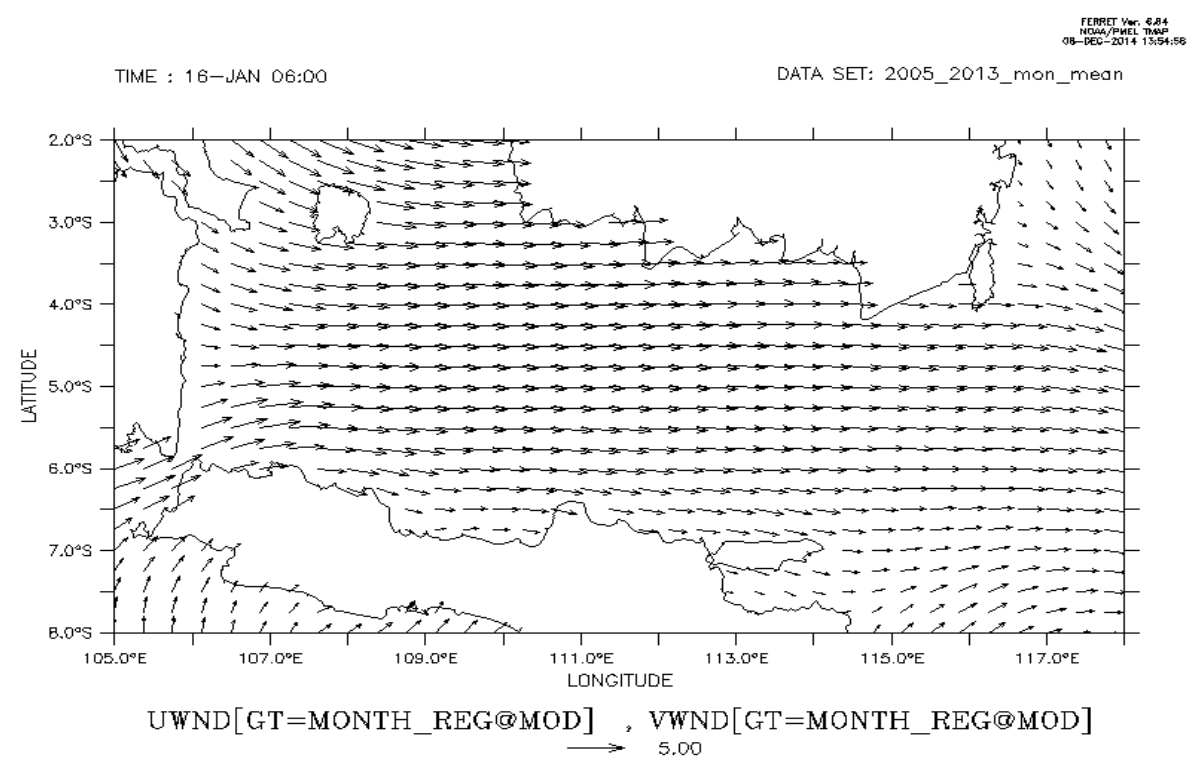

Gambar 5. Distribusi pola angin di Laut Jawa rerata Januari 2005-2013

Di Laut Jawa rerata kecepatan angin tertinggi terjadi pada puncak musim barat (Januari) mencapai 4-6 meter/detik, dan musim timur (Agustus) 4-8,5 meter/detik, berdasarkan rerata 9 tahunan (2005-2013), lihat Gambar 5 dan Tabel 1. Hal ini terjadi karena minimnya pengaruh angin dari Laut Cina Selatan dan dari Samudera Hindia Tenggara (lihat Gambar 2 3). Adapun karakteristik topografi wilayah Laut Jawa merupakan wilayah tertutup sehingga medan angin yang diperoleh tidak seluas seperti wilayah Selat Karimata.

\section{Karakteristik Gelombang Signifikan}

Karakteristik gelombang signifikan yang dibangkitkan oleh angin di Selat Karimata dan Laut Jawa terjadi musim barat (Januari) dan musim timur (Agustus) pada setiap tahunnya, lihat Tabel 1. Khususnya pada puncak musim barat (Januari), gelombang signifikan mencapai 1,5-3 meter di Selat Karimata, dan 0,5-2,5 meter di Laut Jawa. Ekstensifikasi frekuensi kemunculannya sering terjadi hingga bulan Februari, dimana tinggi gelombang signifikan di Laut Jawa kisarannya adalah tetap (0,5-2,5 meter), sedangkan di Selat Karimata sedikit mengalami penurunan (1-2,5 meter). Lihat Gambar 6 - 7 dan Tabel 1. 


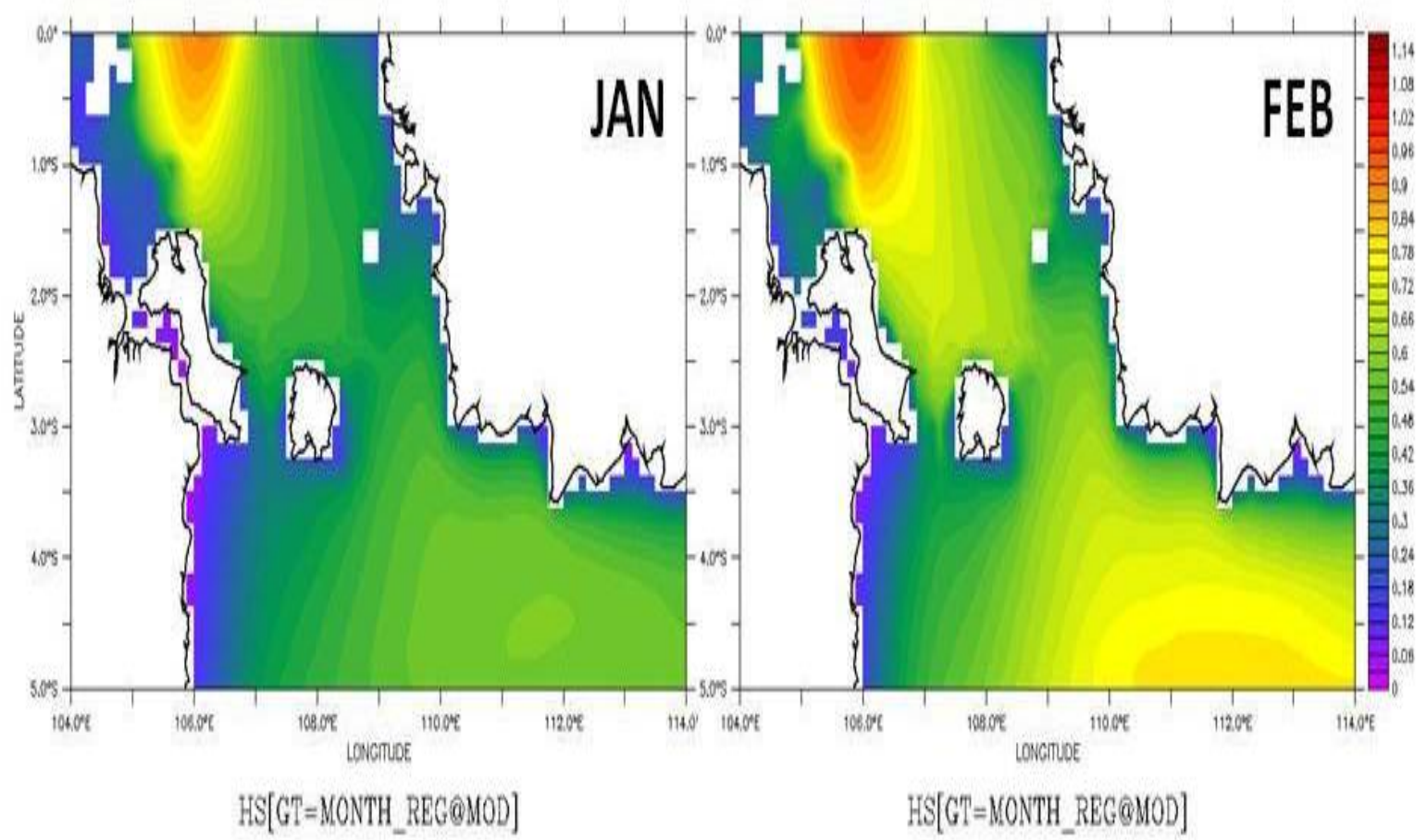

Gambar 6. Gelombang signifikan di Selat Karimata untuk Januari dan Februari berdasarkan rerata angin 9 tahunan (2005-2013)

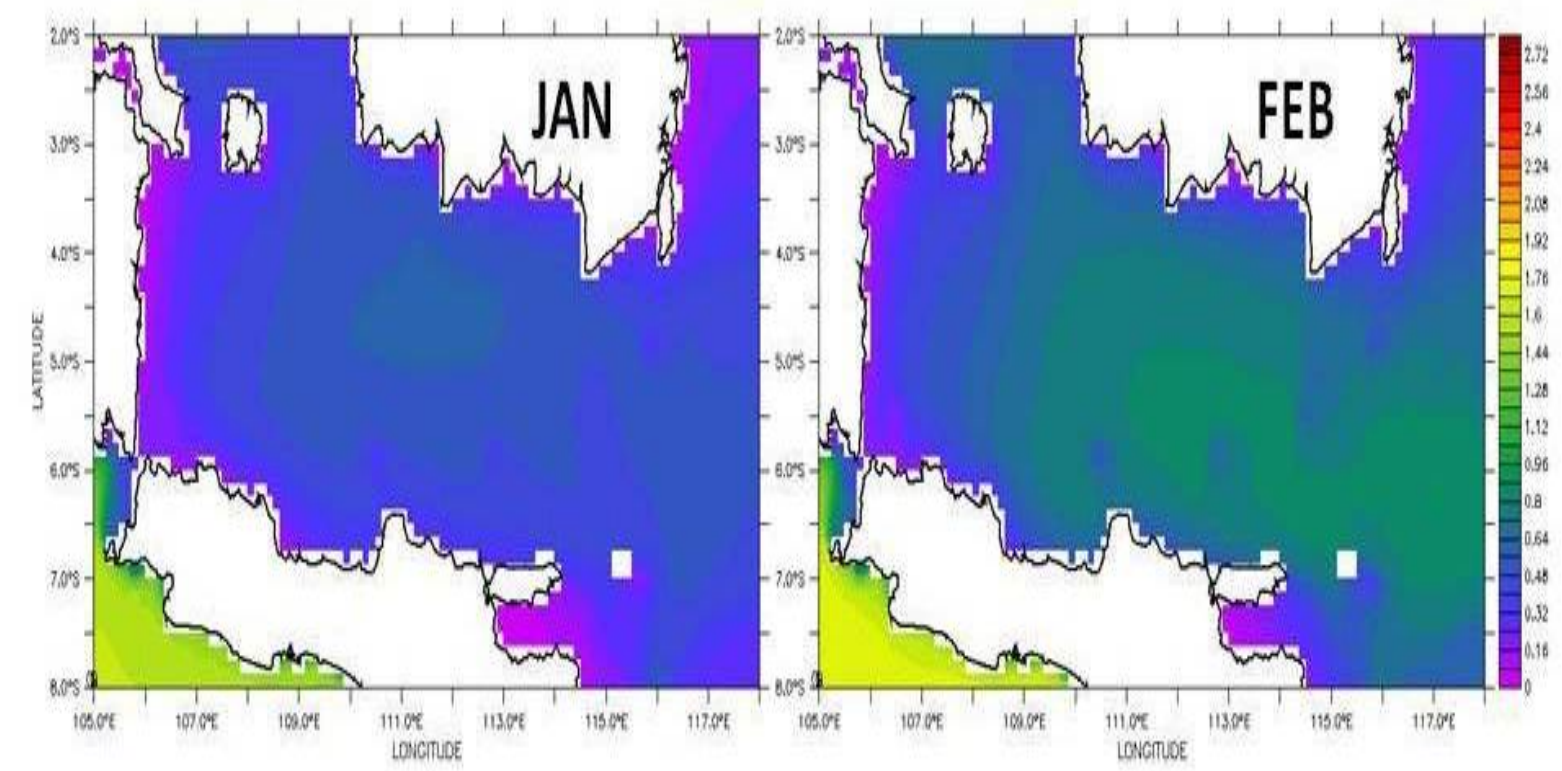

Gambar 7. Gelombang signifikan di Laut Jawa untuk Januari dan Februari berdasarkan rerata angin 9 tahunan (2005-2013).

Propagasi gelombang signifikan adalah mengikuti pola pergerakan angin. Gelombang signifikan pada periode Januari hingga Februari bergerak dari arah Laut China Selatan memasuki Selat Karimata yang kemudian menuju ke Laut Jawa dan melanjutkan propagasinya ke arah timur. Peredaman tinggi gelombang di Laut Jawa terjadi diakibatkan oleh kondisi batimetri yang mendangkal (slope yang landai).

\section{Rekomendasi Prediksi Gelombang Signifikan Untuk Keselamatan Pelayaran}


Berdasarkan hasil simulasi gelombang signifikan rerata bulanan menggunakan angin bulanan rerata 9 tahunan (2005-2013), direkomendasikan kepada seluruh pengguna transportasi laut, agar menghindari pelayaran di Selat Karimata dan Laut Jawa pada Bulan Januari dan Pebruari, dimana maksimum tinggi gelombang mencapai 2,5-3 meter. Demikian juga perlu dihindari pada Nopember dan
Desember (lihat Tabel 1). Rekomendasi ini ditujukan kepada kapal-kapal yang tinggi lambung (timbulnya) kurang dari 3 meter. Selain dari faktor tinggi kapal, tentunya ada beberapa faktor lain yang mempengaruhi keselamatan dalam pelayaran yang tetap perlu diperhatikan, seperti contohnya yakni agar kapal tidak mengangkut muatan yang melebihi daya kapasitas muat.

Tabel 1. Rerata 9 tahunan (2005-2013) kecepatan angin dan tinggi gelombang di Selat Karimata dan Laut Jawa

\begin{tabular}{|c|c|c|c|c|c|}
\hline \multirow[t]{2}{*}{ NO } & \multirow[t]{2}{*}{ BULAN } & \multicolumn{2}{|c|}{ SELAT KARIMATA } & \multicolumn{2}{|c|}{ LAUT JAWA } \\
\hline & & $\begin{array}{l}\text { ANGIN } \\
(\mathrm{m} / \mathrm{dt})\end{array}$ & $\begin{array}{c}\text { GELOMBANG } \\
(\mathrm{m})\end{array}$ & $\begin{array}{l}\text { ANGIN } \\
(\mathrm{m} / \mathrm{dt})\end{array}$ & GELOMBANG (m) \\
\hline 1. & JANUARI & $5-8$ & $1,5-3$ & $4-6$ & $0,5-2,5$ \\
\hline 2. & FEBRUARI & $3,5-8$ & $1-2,5$ & $4-6$ & $0,5-2,5$ \\
\hline 3. & MARET & $2-3,5$ & $1,5-2,5$ & $2-4$ & $1-1,5$ \\
\hline 4. & APRIL & $0,5-1,5$ & $1-1,5$ & $0,5-2$ & $0,5-1,5$ \\
\hline 5. & MEI & $1,5-3$ & $1-1,5$ & $1,5-3$ & $1-1,5$ \\
\hline 6. & JUNI & $4-6$ & $1,5-2$ & $3,5-5$ & $1-2$ \\
\hline 7. & JULI & $4,5-5,5$ & $1,5-2,5$ & $4-6$ & $1-2$ \\
\hline 8. & AGUSTUS & $5-9$ & $1-2,5$ & $4-8,5$ & $1-3$ \\
\hline 9. & SEPTEMBER & $5-8$ & $1-2,5$ & $5-7$ & $0,5-2$ \\
\hline 10. & OKTOBER & $1,5-3$ & $1-2$ & $1-3$ & $1-1,5$ \\
\hline 11. & NOPEMBER & $1-3$ & $0,5-1,5$ & $1-2,5$ & $0,5-1,5$ \\
\hline 12. & DESEMBER & $3-5$ & $1-2$ & $2,5-4,5$ & $1-1,5$ \\
\hline
\end{tabular}

\section{KESIMPULAN DAN REKOMENDASI}

\section{Kesimpulan}

Karakteristik gelombang signifikan yang dibangkitkan oleh angin di Selat Karimata dan Laut Jawa terjadi musim barat (Januari) dan musim timur (Agustus) pada setiap tahunnya. Khususnya pada puncak musim barat (Januari), gelombang signifikan mencapai 1,5-3 meter di Selat Karimata, dan 0,5-2,5 meter di Laut Jawa. Ekstensifikasi frekuensi kemunculannya sering terjadi hingga bulan Februari, dimana tinggi gelombang signifikan di Laut Jawa kisarannya adalah tetap (0,5-2,5 meter), sedangkan di Selat Karimata sedikit mengalami penurunan (1-2,5 meter). Direkomendasikan kepada seluruh pengguna transportasi laut, agar menghindari pelayaran di Selat Karimata dan Laut Jawa pada Bulan Januari dan Pebruari, dengan menggunakan tinggi lambung kapal kurang dari 3 meter.

Saran

Kepada mahasiswa yang tertarik dengan penelitian tugas akhir tentang gelombang disarankan agar menggunakan pemodelan WaveWatch III, karena pemodelan ini bersifat open source atau dapat digunakan oleh seluruh pengguna yang berkepentingan dengan jalur lalu lintas pelayaran. Contohcontoh dalam parameter-parameter yang digunakan dalam pengambilan dan pengembangan model ini cukup variatif. Satelit sebagai data pembanding masih memiliki kekurangan dalam ketersediaan data sehingga kurang mewakili kondisi sebenarnya. 


\section{DAFTAR PUSTAKA}

BPS, 2014. Jumlah dan kepadatan penduduk indonesia. http://www.bps.go.id (diakses pada 20 Agustus 2014).

Deny, M.W., 2004, Ocean Waves, Nearshore Ecology And Natural Selection, Stanford University, Hopkins Marine Station, Pasific Grove, USA.

Hankin, S., Callahan, J., Manke, A., O'Brien, K., Li, J., 2007. FERRET User's Guide Ver. 6.02. NOAA/PMEL/TMAP. 609 pages.

Holthuijen, L. H 2007.Waves In Oceanic And Coastal Waters. New York, Cambride University Press.

Kurniawan, R., Habibie, M.N., Permana, D.S., 2012. Kajian Daerah Rawan Gelombang Tinggi di Perairan Indonesia, Pusat Penelitian dan Pengembangan BMKG.

Pranowo, W.S., 2014. Adjustment Computation. Semester II S1/XXXIV 2014. Lecture Module. Department of Tech. Hidro-Oceanography, Indonesian Naval Post-Graduate School (STTAL). Jakarta.

Purba, N.P, dan W. Pranowo, 2015. Dinamika Oseanografi, Deskripsi Karakteristik massa Air, dan Sirkulasi Laut. ISBN: 978-602-0810-20-1. Unpad Press. 276 halaman.

Pranowo, W.S., 2012. Dinamika Upwelling dan Downwelling di Laut Arafura dan Timor, J. Widya Riset, Vol. 15, No. 2, ISSN:1411-7932, p. 415-424.

Pranowo, W.S., T.R. Adi, S. Makarim, \& N.N. Hasanah. 2012. Marine \& Climate Research Contributions to the National Program on Climate Change Adaptation \& Mitigation. Procced. The International Workshop on Climate Information Services in Supporting Mitigation \& Adaptation to Climate Change in Transportation \& Tourism. 15-16 May 2012. ISBN:978-60219508-3-8. p.76-79.

Saha, S., S. Moorthi, X. Wu, J. Wang, S. Nadiga, P. Tripp, D. Behringer, Y.-T. Hou, H.-y. Chuang, M. Iredell, M. Ek,
J. Meng, R. Yang, M.P. Mendez, H.v.d. Dool, Q. Zhang, W. Wang, M. Chen, and E. Becker., 2014. The NCEP Climate Forecast System Version 2. J. Climate, 27, 2185-2208. doi: http://dx.doi.org/10.1175/JCLI-D12-00823.1.

Sofian, I., A. Supangat., M.S. Fitriyanto, R. Kurniawan. 2011. Memahami dan Mengantisipasi Dampak Perubahan Iklim pada Pesisir dan Luat di Indonesia Bagian Timur. Jurnal Meteorologi dan Geofisika 12(1) 2011: 53-64.

Sofian, I., 2010. Scientific Basis: Analysis and Projection Sea Level Rise and Extreme Weather Event Report. ICCSR Report. Ministry for National Development Planning. pp.89.

Sofian, I., Kozai, K., \& Ohsawa, T., 2008. Investigation on the relationship between wind-induced volume transport and mean sea level in the Java Sea using an oceanic general circulation model. Journal of Marine and Meteorological Society of Japan, Umitosora, Volume 84.

Sofian, I., \& A.B. Wijanarto. 2008. Kenaikan Tinggi Muka Laut di Jakarta berdasarkan IPCC AR4, Jurnal Geomatika, Vol. 14(2), 71-80.

Tolman, H. L. 2002. User manual and system documentation of WAVEWATCH-III version 2.22, NOAA/NWS/NCEP, 110 pp. U.S Departement of Commerce National Oceanic and Atmospheric Administration National Weather Service National Centers for Environmental Prediction 4700 Silver Hill Road, Mail Stop Washington, DC 20233-9910.

Tolman, H. L., \& D. V. Chalikov. 1996. Source terms in a third-generation wind wave model, Journal of Phys. Oceanography, 26, 2497-2518.

WMO, 2008. Java Sea, chapter 6 South china and Eastern archipelagic seas And its sub-divisions Chartlet-index 23WG.http://www.iho.int/mtg_docs/co m_wg/S-23WG/S-23 . (diakses pada 4 Desember 2014). 